Verhalten konfrontiert, und auch der gewohnte Geruch kann sich verändern. In dieser Situation versucht das Tier, durch Stupsen und Lecken Aufmerksamkeit zu erregen. Klappt das nicht, beginnt es zu beißen." Möglich sei auch, dass die durch das Ableben gekippte Hierarchie Mensch-Tier eine Rolle spiele und der Hund nun seinerseits den Dominator herauskehre. Unklar ist übrigens auch, weshalb sich unter den besonders rabiaten postmortalen Beißern so häufig Deutsche Schäferhunde finden.

\section{Tote bluten kaum}

Fehlen massive Ausblutung und subkutane Hämatome, lässt dies darauf schließen, dass die Verletzungen erst nach dem Tod verursacht wurden. Allerdings warten nicht alle Vierbeiner so lange, bis der Exitus eingetreten ist. Das kompliziert die Befundlage zusätzlich. Schon vor Jahren berichteten Freiburger Rechtsmediziner um Maria Faller-Marquardt von einer 57-jährigen Frau, die nach einem hämorrhagischen zerebralen Insult das Bewusstsein verloren hatte. Ihre acht Mischlingshunde (zwei erwachsene Tiere, sechs Welpen) bissen ihr ein $10 \times 9 \times 3 \mathrm{~cm}$ großes Stück aus dem rechten Oberschenkel und fügten ihr zahlreiche weitere kleinere Verletzungen zu - und zwar noch während sie lebte. Folgern ließ sich das aus den Zeichen vitaler Reaktionen, unter anderem aus Hämatomen an den Wundrändern (Beitr Gerichtl Med 1992; 50: 351-6).

\section{Wenn der Biss trügt}

Postmortaler Hundeverbiss weckt bei den Untersuchern oft den Verdacht auf eine kriminelle Handlung. Er kann aber auch davon ablenken. Einen solchen Fall hat ebenfalls Michael Tsokos untersucht (Arch Kriminol 2000; 206: 30-7). Es ging dabei um eine 20-jährige Frau, deren nahezu nackte Leiche, im Bett auf dem Rücken liegend, vor gut zehn Jahren von der Polizei in einem Hamburger Apartment entdeckt worden war. Der rechte Oberschenkel wies an seiner Innenseite einen $20 \times 40 \mathrm{~cm}$ großen Gewebedefekt auf. Von den zerklüfteten Wundrändern und oberflächlichen Kratzspuren, der Art nach post mortem entstanden, schlossen die Beamten auf den Schuldigen, einen Mischlingshund, der sich ebenfalls im Raum befand. Da sie ansonsten keine Zeichen von Gewalteinwirkung fanden und die Tote zudem in der Drogenszene bekannt war, nahmen die Polizisten eine Überdosis als Todesursache an.

Bei der Autopsie zeigten sich indes 13 Stichwunden am Nacken und Strangulationszeichen am Hals der Frau. Zudem hatte sie vor ihrem Tod Blut aspiriert. Die Diagnose lautete schließlich auf Sexualmord. Der Hund schied hier als Täter aus.

DR. ROBERT BUBLAK *

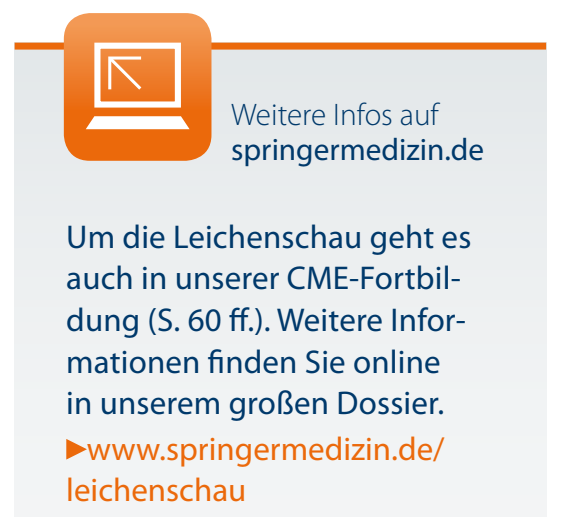

\title{
Der Schäferhund ist nicht immer der Mörder
}

Die Initiative zum Leichenfraß muss allerdings nicht immer vom Hund ausgehen. Davon zeugt eine Begebenheit, für die sich vor einigen Jahren ein 19-jähriger New Yorker vor Gericht verantworten musste (Am J Forensic Med Pathol 2000; 21: 389-94). Er war eines Morgens von seiner Freundin geweckt worden, die nach dem Aufwachen ihrer beider Baby nicht mehr in seinem Bettchen gefunden hatte. Die Spuren ließen scheinbar nur einen Schluss zu: Der Hund des Paares, ein 40 Kilo schwerer Schäferhund, hatte sich über den erst sechs Tage alten Sohn hergemacht.

Als die Polizei eintrifft, findet sie den Teppich im Zimmer blutverschmiert, eine blutige Windel, einen blutbefleckten Babypyjama, Stücke von menschlichem Fleisch und Fragmente von Schädelknochen. Daneben steht der Hund. Bisher war er wohl beleumundet, er galt als freundlich. Nun hat er Blut an den Vor-

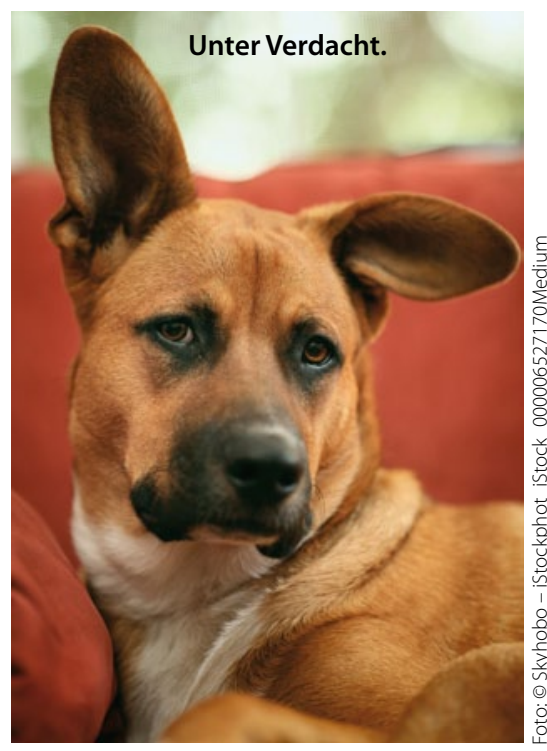

derpfoten. Die Polizisten entscheiden, ihn untersuchen zu lassen, und fahren mit ihm zum Röntgen. Er hat Knochen im Bauch. Das kostet ihn sein Hundeleben, bei der Autopsie finden die Gerichtsmediziner Überreste des Säuglings. Doch viele Körperteile fehlen. Und die vorhandenen Gewebe weisen kaum Hämorrhagien auf. Dem Anschein nach sind die Glieder erst nach dem Tod des Kindes voneinander getrennt worden aber nicht durch Hundebisse, sondern mit einem Messer.

Damit konfrontiert, gesteht der Vater des Kindes, seinen Sohn nachts aus Wut Kopf voraus zu Boden geschleudert zu haben, worauf der Schädel geborsten sei. Das tote Kind habe er zerlegt und Teile an den Hund verfüttert, den Rest in der Toilette entsorgt. Der Grund für die Wut: Beim Wickeln des Kindes war etwas schiefgelaufen.

Im Zweifelsfall ist der Mensch eben doch das schlimmere Tier. 